\title{
Effects of inhaled $\beta$ agonist and corticosteroid treatment on nuclear transcription factors in bronchial mucosa in asthma
}

\author{
Robert J Hancox, David A Stevens, Ian M Adcock, Peter J Barnes, D Robin Taylor
}

\begin{abstract}
Background-Inhaled corticosteroids and $\beta$ agonists are the most commonly used treatments in asthma and are often used together. Recent evidence suggests that many of the anti-inflammatory actions of corticosteroids are mediated by cross-talk between the activated glucocorticoid receptor (GR) and other transcription factors such as the pro-inflammatory nuclear factor kappa B (NFkB). Beta agonists can activate the transcription factor cAMP response element binding protein (CREB). A mutual inhibition between GR and CREB occurs in vitro which raises the possibility of a negative interaction between corticosteroid and $\beta$ agonist drugs. $A$ study was undertaken to determine whether these interactions occur during treatment with $\beta_{2}$ agonists and corticosteroids in asthma.

Methods-Seven subjects who were participating in a randomised, placebo controlled, crossover study of six weeks treatment with inhaled budesonide (400 $\mu \mathrm{g}$ twice daily), terbutaline (1 $\mathrm{mg}$ four times daily), and combined treatment were recruited. Biopsy samples of the bronchial mucosa were obtained after each treatment and analysed for the DNA binding activity of GR, CREB, and NFкB. Results-Budesonide increased GR activity $(p<0.05)$ and decreased NFKB activity $(p<0.05)$. No treatment combination altered CREB activity and terbutaline had no significant effects on any transcription factor.

Conclusions-Inhaled corticosteroids have significant effects on GR and NFKB activity in bronchial mucosa. A negative interaction between inhaled corticosteroids and $\beta$ agonists was not found.

(Thorax 1999;54:488-492)
\end{abstract}

Keywords: inhaled corticosteroids; $\beta_{2}$ agonists; transcription factors

Corticosteroids have potent anti-inflammatory effects which are beneficial in the treatment of asthma. The mechanisms of their antiinflammatory action have been extensively investigated in recent years and are believed to be mediated by altering gene expression. This may occur directly by the binding of the activated glucocorticoid receptor (GR) to glucocorticoid response elements (GREs) in the promoter region of target genes or indirectly via the ability of the GR to interact with other nuclear transcription factors thereby enhancing or suppressing their effects. ${ }^{1}$ This cross-talk between transcription factors can occur at the level of DNA binding where GREs occur close to binding sites for other transcription factors. $^{2}{ }^{3}$ Transcriptional cross-talk may also occur due to direct protein-protein interactions between transcription factors or by binding of co-factors such as the cAMP response element binding protein (CREB) binding protein (CBP) and P300 which may be necessary for gene transcription. ${ }^{4}$

The GR has been shown to interact with the pro-inflammatory transcription factor nuclear factor kappa B (NFKB) by binding to the p65 subunit of the NFKB heterodimer. ${ }^{5}$ This suppresses the DNA binding activity of $\mathrm{NF} \mathrm{B}^{56}$ and prevents transcription of inflammatory genes such as those for the cytokines interleukins 6 and $8 .^{57} \mathrm{NF \kappa B}$ regulates genes for many of the cytokines, inflammatory enzymes, and adhesion molecules which are activated in asthma, and thus inhibition of $\mathrm{NF \kappa B}$ binding may be an important mechanism of the anti-inflammatory effects of corticosteroids. ${ }^{1}$

Conversely, other transcription factors may inhibit the activity of corticosteroids through similar mechanisms. ${ }^{59}$ An interaction between the GR and CREB has been demonstrated in rat lung in vitro. Incubation with corticosteroids enhances GR binding to DNA whereas incubation with $\beta$ agonists increases CREB binding to DNA. Simultaneous incubation with both drugs causes a reciprocal reduction of the increase in binding of both GRs and CREB by $40-50 \% .{ }^{10}$ As a consequence, $\beta$ agonists may inhibit the anti-inflammatory activity of corticosteroids.

The relevance of these in vitro findings to the treatment of asthma is unclear. Many patients use both inhaled corticosteroids and $\beta$ agonists for the treatment of asthma, raising the possibility that there may be a negative interaction in vivo between the two drugs. This has not been extensively investigated in the clinical setting although two recent studies have found that the beneficial effects of inhaled budesonide on the early asthmatic response to allergen are reduced by concomitant treatment with inhaled $\beta$ agonists. ${ }^{11}{ }^{12}$

This study was part of a larger investigation of the effects of inhaled corticosteroids and $\beta_{2}$ agonists in asthma ${ }^{13}$ and was designed to examine the effects of each drug singly and in 
combination on transcription factor binding in bronchial mucosa.

\section{Methods \\ SUBJECTS}

The inclusion criteria for the study have been reported previously. ${ }^{13}$ Briefly, non-smoking subjects with mild to moderate atopic asthma and evidence of bronchial hyperresponsiveness $\left(\mathrm{PC}_{20}\right.$ methacholine $\left.\leqslant 8 \mathrm{mg} / \mathrm{ml}^{14}\right)$ were recruited. For this subgroup study all subjects who had successfully completed the run in to the principal study were invited to participate before starting on the first of the blinded treatments. Other than restricting participation to adults (aged $\geqslant 18$ years), subjects were unselected. Recruitment commenced when ethical approval for this subgroup study had been obtained and finished when the target number of subjects (6) had been exceeded.

\section{STUDY DESIGN}

The study design has been reported in detail elsewhere. ${ }^{13}$ Following a four week run in period subjects were assigned to a double blind, random sequence of the following four treatments: (1) budesonide $400 \mu \mathrm{g}$ twice daily + terbutaline $1 \mathrm{mg}$ four times daily; (2) budesonide $400 \mu \mathrm{g}$ twice daily + placebo four times daily; (3) placebo twice daily + terbutaline $1 \mathrm{mg}$ four times daily; (4) placebo twice daily + placebo four times daily. Drugs were given by Turbuhaler (Astra Draco, Lund, Sweden). Each treatment was given for six weeks with a four week washout between each treatment period. During the run in and washout periods subjects used identical inhalers containing placebo (single blind). Inhaled ipratropium bromide (Atrovent Forte, Boehringer Ingelheim, Germany) was used for symptom relief throughout the study and subjects were instructed not to take any other asthma treatment (including nasal corticosteroids) except in an emergency.

BRONCHOSCOPY PROCEDURE

The primary end point of this study was the analysis of GR, CREB, and NFkB binding to DNA in bronchial mucosa samples obtained by fibreoptic bronchoscopy at the end of each treatment period. After measurement of the pulmonary function end points required for the principal study, ${ }^{13}$ subjects continued treatment for a further 3-7 days before the bronchoscopic procedure.

Subjects were instructed to fast and not to take their study inhalers or ipratropium inhaler for six hours before bronchoscopy. On arrival asthma stability was assessed and forced expiratory volume in one second $\left(\mathrm{FEV}_{1}\right)$ was measured (Vitalograph, UK) to ensure that it was safe to proceed with bronchoscopy $\left(\mathrm{FEV}_{1}\right.$ $>50 \%$ predicted). Premedication was given with intravenous atropine $0.6 \mathrm{mg}$ and intravenous pethidine $25-50 \mathrm{mg}$. Subjects then inhaled nebulised lignocaine $(1 \%)$ for $10 \mathrm{~min}$ utes. Lignocaine jelly ( $2 \%$ ) was applied to the nostril prior to inserting the bronchoscope and further lignocaine solution $(1 \%)$ was sprayed into the airway as required during the procedure. Additional sedation (intravenous alfentanyl $0.5-1 \mathrm{mg}$ ) was given as required. Supplemental oxygen $21 / \mathrm{min}$ was given throughout and pulse oximetry was monitored continuously.

Several biopsy specimens (5-8) were obtained at the level of second order carinae from the right middle and lower lobe bronchi. These were snap frozen in liquid nitrogen within 15-20 minutes.

All subjects received nebulised salbutamol $2.5 \mathrm{mg}$ on completion of the bronchoscopy. Spirometric tests were repeated $10-15$ minutes later. After a period of observation subjects were allowed to leave.

\section{TRANSCRIPTION FACTOR ANALYSIS}

Biopsy samples were kept at $-70^{\circ} \mathrm{C}$ until the study was complete. They were then transferred on dry ice to the National Heart and Lung Institute in London. Nuclear and cytosolic proteins were extracted from biopsy tissue and transcription factor binding was measured by electrophoretic mobility shift assay as previously described. ${ }^{15}$

In brief, cells were lysed with $200 \mu \mathrm{l}$ buffer $\mathrm{A}$ (20 mM HEPES, $1.5 \mathrm{mM} \mathrm{MgCl}_{2}, 10 \mathrm{mM}$ $\mathrm{KCl}, 0.5 \mathrm{mM}$ DTT, $0.1 \%$ Nonidet P40) and incubated at $4^{\circ} \mathrm{C}$ for 15 minutes. After microcentrifugation for 10 seconds and collection of the cytosolic fraction, the nuclear pellet was lysed with $20 \mu \mathrm{l}$ of buffer B (20 mM HEPES, $1.5 \mathrm{mM} \quad \mathrm{MgCl}_{2}, 0.42 \mathrm{mM} \mathrm{NaCl}, 0.5 \mathrm{mM}$ DTT, $25 \%$ glycerol, $0.5 \mathrm{mM}$ PMSF, $0.2 \mathrm{mM}$ EDTA). The subsequent soluble fraction was mixed with $100 \mu$ of buffer $\mathrm{C}$ (20 mM HEPES, $50 \mathrm{mM} \mathrm{KCl}, 0.5 \mathrm{mM}$ DTT, $0.5 \mathrm{mM}$ PMSF, $0.2 \mathrm{mM}$ EDTA). $2 \mu \mathrm{g}$ nuclear protein from each sample was preincubated at $4^{\circ} \mathrm{C}$ for 30 minutes in binding buffer $(10 \mathrm{mM}$ Tris $\mathrm{HCl}$, $\mathrm{pH} 7.5,1 \mathrm{mM} \mathrm{MgCl}_{2}, 0.5 \mathrm{mM}$ EDTA, $0.5 \mathrm{mM}$ DTT, $50 \mathrm{mM} \mathrm{NaCl}, 4 \%$ glycerol, $0.1 \mu \mathrm{g} / \mu \mathrm{l}$ salmon sperm DNA). Double stranded oligonucleotides encoding the specific sequences of GRE (5'-TCGACT GTACAGGATGTTCTAGCTACT-), NFкB (5'-AGTTGAGGGGACTTTCCCAGGC-), CRE (5'-AGAGATTGCCTGACGTCAGA GAGCTAG-) and Oct-1 (TGTCGAATG CAAATCACTAGAA) (Promega, Cambridge, UK) were end-labelled with $\left(\gamma-{ }^{32} \mathrm{P}\right)$-ATP and T4 polynucleotide kinase. Each sample was incubated with $50000 \mathrm{cpm}$ of labelled oligonucleotide for 40 minutes at $4^{\circ} \mathrm{C}$. The protein-DNA complexes were separated on a $6 \%$ polyacrylamide gel using Tris-BorateEDTA running buffer. Gels were autoradiographed for 1-3 days using Kodak OMAT XS film at $-70^{\circ} \mathrm{C}$ with an intensifying screen and analysed by laser densitometry using a PDI image analysis system which covers a 3 OD unit range (Protein Databases Inc, New York, USA). Specificity of binding was determined by adding excess unlabelled oligonucleotide. Binding of the transcription factors GR, $\mathrm{NF \kappa B}$, and CREB was expressed as a percentage of the binding of the transcription factor Oct-1 (fig 1). 
A

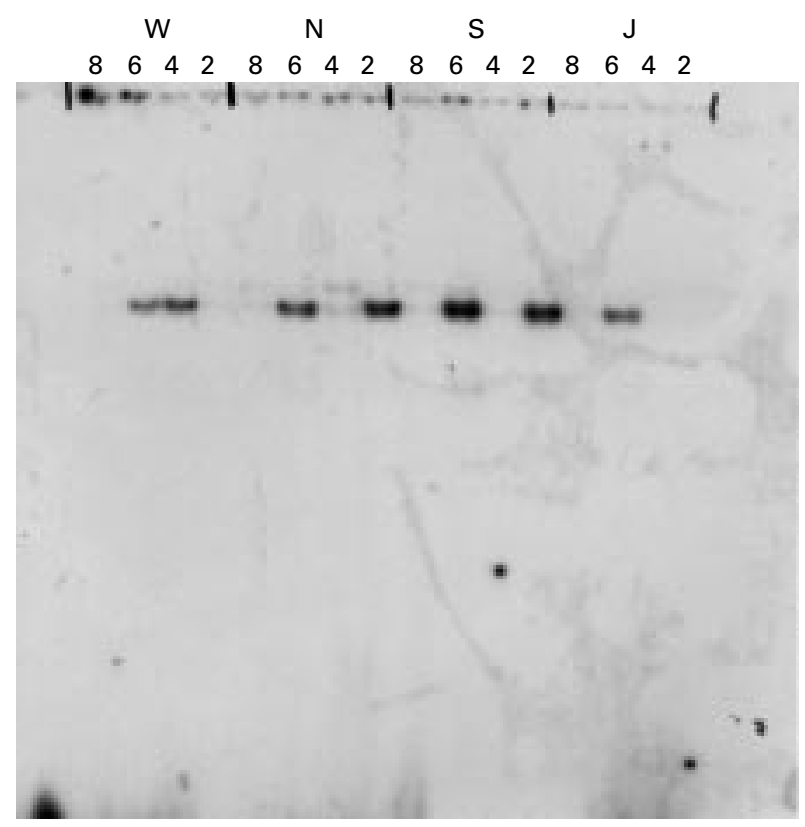

C

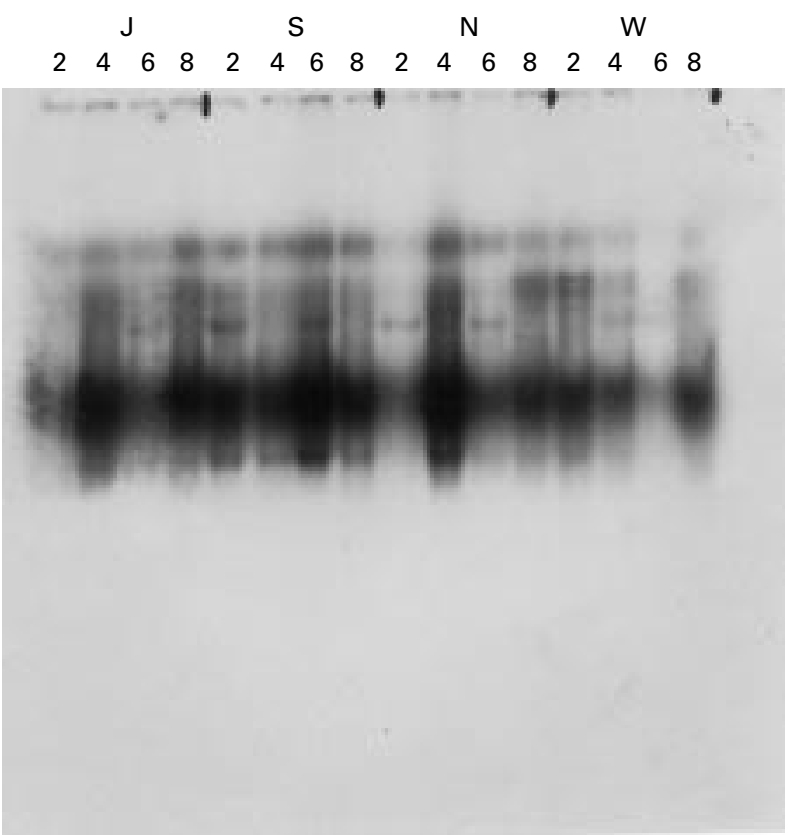

B

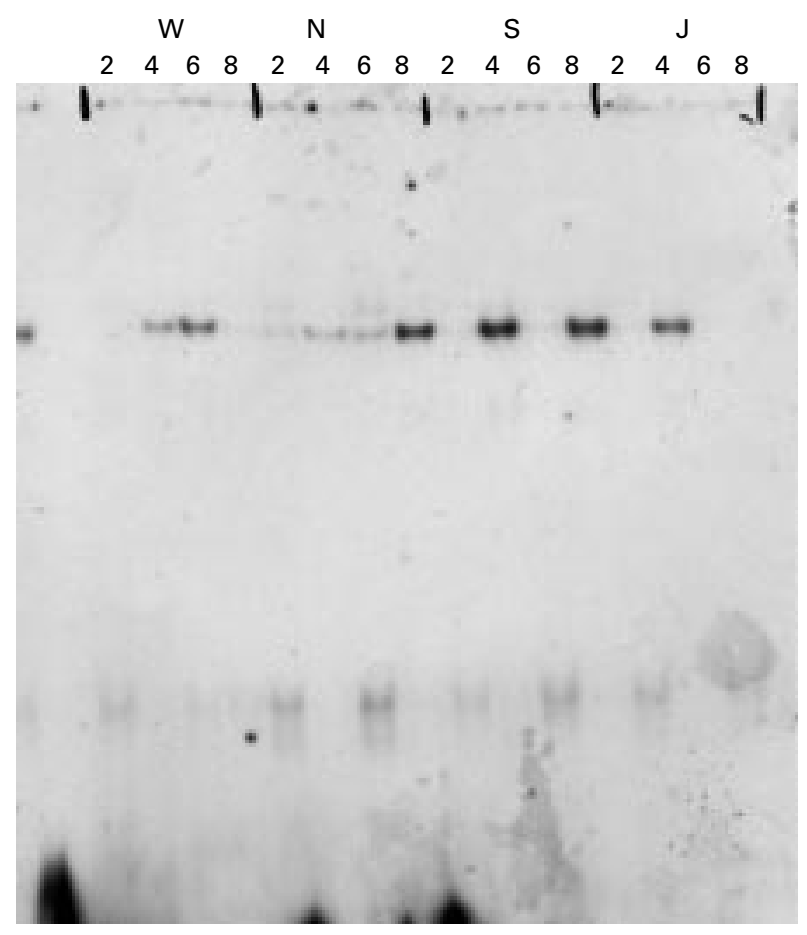

D
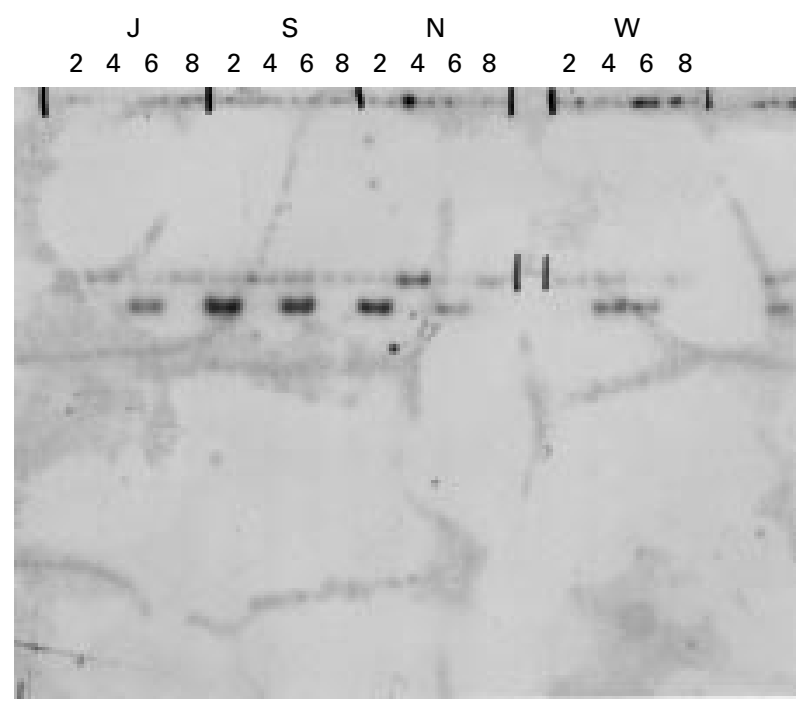

Figure 1 Representative gels for four subjects for (A) GRE, (B) CREB, (C) $N F \kappa B$, and (D) Oct-1. For each subject lanes 2, 4, 6 and 8 are from the four treatment periods.

ensure patient safety. ${ }^{16}$ Subjects had access to the investigators at all times, and clear instructions for the emergency treatment of an asthma exacerbation in the form of an individualised action plan were given to all subjects. The study was approved by the Otago ethics committee. Written informed consent was obtained from each subject before entering the study and before each bronchoscopic procedure.

\section{Results}

SUBJECTS

All seven subjects (one male, age 18-45) completed the study. The mean (SD) duration of 
Table 1 Transcription factor binding to DNA during each treatment period (as \% of Oct-1 binding)

\begin{tabular}{|c|c|c|c|c|c|c|c|c|c|c|c|c|}
\hline \multirow[b]{2}{*}{ Subject } & \multicolumn{4}{|c|}{ GR binding } & \multicolumn{4}{|c|}{$C R E B$ binding } & \multicolumn{4}{|c|}{$N F \kappa B$ binding } \\
\hline & $P$ & $T$ & $B$ & $B T$ & $P$ & $T$ & $B$ & $B T$ & $P$ & $T$ & $B$ & $B T$ \\
\hline 1 & 0.76 & 0.76 & 0.93 & 1.52 & 0.40 & 0.43 & 0.55 & 0.64 & 8.11 & 7.06 & 4.63 & 8.29 \\
\hline 2 & 1.00 & 0.65 & 1.18 & 2.91 & 0.56 & 0.40 & 0.62 & 0.40 & 14.25 & 11.29 & 2.39 & 4.66 \\
\hline 3 & 0.92 & 0.75 & 0.76 & 0.88 & 0.51 & 0.29 & 0.48 & 0.48 & 1.39 & 8.03 & 5.83 & 3.26 \\
\hline 4 & 0.97 & 0.72 & 1.02 & 1.60 & 0.85 & 1.47 & 1.10 & 0.71 & 20.33 & 7.12 & 5.88 & 14.33 \\
\hline 5 & 0.56 & 0.34 & 0.88 & 0.66 & 0.31 & 0.41 & 0.51 & 0.51 & 9.33 & 10.10 & 4.25 & 4.10 \\
\hline 6 & 1.06 & 1.38 & 1.85 & 1.38 & 1.74 & 2.14 & 0.74 & 1.25 & 13.10 & 14.88 & 18.10 & 0.99 \\
\hline 7 & 0.74 & 0.55 & 0.6 & 0.84 & 0.54 & 1.11 & 0.28 & 0.68 & 1.79 & 18.50 & 5.52 & 13.66 \\
\hline Mean & 0.86 & 0.74 & 1.03 & 1.40 & 0.70 & 0.89 & 0.61 & 0.67 & 9.76 & 11.00 & 6.66 & 7.04 \\
\hline SD & 0.16 & 0.30 & 0.38 & 0.70 & 0.45 & 0.65 & 0.24 & 0.26 & 6.32 & 3.99 & 4.81 & 4.84 \\
\hline
\end{tabular}

$\mathrm{GR}=$ glucocorticoid receptor $\mathrm{CREB}=\mathrm{cAMP}$ response element binding protein; $\mathrm{NF \kappa B}=$ nuclear factor kappa $\mathrm{B} ; \mathrm{P}=$ placebo; $\mathrm{T}$ $=$ terbutaline; $\mathrm{B}=$ budesonide; $\mathrm{BT}=$ budesonide + terbutaline

their asthma was $21(9.5)$ years. On entry to the study the mean (SD) $\mathrm{FEV}_{1}$ was 100 (19)\% predicted. Geometric mean $\mathrm{PC}_{20}$ methacholine was $1.37 \mathrm{mg} / \mathrm{ml}$ (range 0.09-5.32). Only two of the subjects were using regular inhaled corticosteroid treatment before entering the study. Two subjects had exacerbations of asthma during one of the treatment periods requiring oral prednisone (both were receiving budesonide + placebo). Without unblinding either the patients or the investigators, these treatments were repeated without further incident at the end of the scheduled treatment sequence.

TRANSCRIPTION FACTORS

The results of the transcription factor binding analysis are shown in table 1 .

\section{GR binding}

Budesonide significantly increased GR binding by a mean of $52 \%$ (95\% CI 6 to 99$)$ ( $p=$ 0.033). There was a trend to higher GR binding when budesonide was combined with terbutaline but this did not reach statistical significance $(p=0.19)$. Terbutaline did not affect GR binding.

\section{CREB binding}

CREB binding was similar during all treatment periods. Although there were trends to higher levels of CREB binding (mean increase 19\% (95\% CI -18 to 55$)$ ) during terbutaline treatment and lower levels of CREB binding (mean decrease 20\% (95\% CI -27 to 66)) during budesonide treatment, neither of these was significant. There was no significant interaction between budesonide and terbutaline on CREB binding.

\section{$N F_{\kappa} B$ binding}

Budesonide significantly reduced $\mathrm{NF \kappa B}$ binding by a mean of $34 \%(95 \%$ CI 5 to 63$)$ ( $p=$ 0.028 ). Terbutaline did not significantly alter $\mathrm{NF} \kappa \mathrm{B}$ binding and there was no significant interaction between budesonide and terbutaline.

\section{Discussion}

The results of this study show that inhaled budesonide causes a small but significant increase in GR binding to DNA in the bronchial mucosa in asthmatic subjects. This increase is in keeping with the results of in vitro studies and with those predicted by the molecular actions of corticosteroids, but the magnitude is reduced. ${ }^{810}$ The failure to demonstrate a greater increase in GR:GRE binding may be due to differences in the concentrations of corticosteroid achieved in the airway in this study and the concentrations used in vitro. Alternatively, the reduced effect could be due to downregulation of the glucocorticoid receptor which has been shown in a number of in vitro and in vivo models. ${ }^{17-21}$

We have also shown for the first time that inhaled corticosteroids reduce binding activity of the pro-inflammatory transcription factor $\mathrm{NF \kappa B}$ in vivo. This confirms the results of in vitro studies which have shown that corticosteroids reduce the level of $\mathrm{NF} \kappa \mathrm{B}$ binding to DNA in human lung tissue and peripheral blood mononuclear cells, ${ }^{56}$ and supports the view that this may be an important mode of action of inhaled corticosteroids. ${ }^{1}$ The exact mechanism of this inhibition is not certain but may be due to a direct protein-protein interaction between GR and the p65 subunit of NFkB. Such a mechanism appears to be responsible for the inhibition of NFKB activation of the IL- 8 promoter by dexamethasone. ${ }^{7}$ Alternatively, the reduction in NFKB DNA binding may reflect an induction of the inhibitor of $\mathrm{NF} \kappa \mathrm{B}$, I $\mathrm{B} \mathrm{B} \alpha$, by budesonide. ${ }^{22}$ Induction of $\mathrm{I} \kappa \mathrm{B} \alpha$ synthesis by corticosteroids is associated with inhibition of $\mathrm{NF \kappa B}$ activity in some cultured mononuclear cells, ${ }^{23} 24$ but studies using other cells have found that the induction of I $\mathrm{B} \alpha$ is neither sufficient nor necessary for the inhibition of $\mathrm{NF} \kappa \mathrm{B}$ transcriptional activity by corticosteroids. ${ }^{25} 26$

In this study we did not find any significant effect of $\beta$ agonist or corticosteroid treatment on the DNA binding activity of CREB. This is in contrast to the results of in vitro studies of lung tissue in which CREB binding was increased by incubation with salbutamol or fenoterol and reduced by incubation with dexamethasone. ${ }^{10}$ Although non-significant trends to an increase in CREB binding during terbutaline and a decrease in CREB binding during budesonide were observed, these changes were small in comparison with the results of in vitro studies. Thus, although this study may have had insufficient power to demonstrate a significant effect, it is clear that the size of the effect is likely to be small. There are several possible reasons for the difference between our results and those obtained in vitro. Firstly, the dose of terbutaline used in this 
study may have been too low to raise intracellular levels of cAMP and thereby activate CREB. Although a standard therapeutic dose was used, it may be that at these doses terbutaline causes smooth muscle relaxation without significant activation of the cAMP pathway. Secondly, the timing of taking the bronchial biopsy specimen with regard to the last dose of the inhaled drugs may have missed their effects on CREB binding. Most of the bronchoscopies were performed in the morning and the interval between the last dose of the study medication and obtaining the biopsy specimen would have been approximately 12 hours. Although $\beta$ agonists produce a sustained increase in CREB activation in vitro, this may be shorter in vivo. Thirdly, the biopsy specimens were of bronchial mucosa rather than lung parenchyma which was used in the in vitro experiments. ${ }^{10}$ It is possible that these tissues differ in their response to increases in intracellular cAMP. Finally, the level of CREB binding in vivo may be subject to homeostatic influences which are not reproduced in tissue culture. During six weeks of maintenance treatment with inhaled $\beta$ agonists there are likely to be counter-regulatory mechanisms which adjust to the effects of sustained activation of $\beta_{2}$ receptors. Downregulation of the $\beta_{2}$ receptor or of its ability to activate CREB, or modulation of the co-factor CBP by other transcription factors are possible mechanisms by which the effects of $\beta$ agonists on gene transcription might be reduced.

This study has failed to confirm the negative interaction between $\beta$ agonists and corticosteroids found in in vitro studies. In rat lung tissue, 24 hours incubation with the $\beta$ agonists fenoterol and salbutamol increases CREB binding to DNA but decreases GR binding. Conversely, incubation with dexamethasone increases GR binding but decreases CREB binding. Incubation with both agents produces a mutual inhibition of their effects. ${ }^{10}$ However, no such interaction was observed during asthma treatment in this study. Similarly, there was no apparent interaction between the effects of budesonide and terbutaline on NFKB binding. This may have been because terbutaline did not produce a sustained activation of CREB, and thus the inhibition of GR binding by CREB would not be expected to have occurred.

In conclusion, the results of the present study suggest that the anti-asthmatic effects of inhaled corticosteroids may be mediated by interactions between the GR and proinflammatory transcription factors such as NFкB. We have been unable to demonstrate any effects of either corticosteroids or $\beta$ agonists on CREB activation. Importantly, there was no evidence that inhaled $\beta$ agonists inhibit the effects of corticosteroids on transcription factors in vivo.

This study was supported by the Asthma Foundation of New Zealand and the National Asthma Campaign in the United Kingdom. Dr Hancox was a Glaxo-Wellcome Research Fellow.
The study medications were provided by Astra Draco. Boehringer Ingelheim provided supplies of ipratropium. The statistical analysis was performed with the assistance of Mr Peter Herbison, Department of Preventive and Social Medicine, University of Otago.

1 Barnes PJ. Mechanisms of action of glucocorticoids in asthma. Am $\mathcal{F}$ Respir Crit Care Med 1996;154:S21-7.

2 Akerblom IE, Slater EP, Beato $M$, et al. Negative regulation by glucocorticoids through interference with a cAMP responsive enhancer. Science 1988;241:350-3.

3 Imai E, Miner JN, Mitchell JA, et al. Glucocorticoid receptor-cAMP response element-binding protein and the response of the phosphoenolpyruvate carboxykinase gene response of the phosphoenolpyruvate carboxykin

4 Janknecht R, Hunter T. Transcriptional control: versatile molecular glue. Curr Biol 1996;8:951-4.

5 Ray A, Prefontaine KE. Physical association and functional antagonism between the p65 subunit of transcription factor $\mathrm{NF \kappa B}$ and the glucocorticoid receptor. Proc Natl Acad Sci USA 1994;91:752-6.

6 Adcock IM, Shirasaki H, Gelder CM, et al. The effects of glucocorticoids on phorbol ester and cytokine stimulated transcription factor activation in human lung. Life Sci 1994;55:1147-53.

7 Mukaida N, Morita M, Ishikawa Y, et al. Novel mechanism of glucocorticoid-mediated gene repression: nuclear factor- $\mathrm{KB}$ is target for glucocorticoid-mediated interleukin 8 gene repression. $\mathcal{F}$ Biol Chem 1994;269:13289-95.

8 Adcock IM, Brown CR, Gelder CM, et al. Effects of glucocorticoids on transcription factor activation in human peripheral blood mononuclear cells. Am f Physiol 1995; 268:C331-8.

9 Schüle R, Rangarajan P, Kliewer S, et al. Functional antagonism between oncoprotein c-Jun and the glucocorticoid receptor. Cell 1990:62:1217-26.

10 Peters MJ, Adcock IM, Brown CR, et al. $\beta$-adrenoreceptor agonists interfere with glucocorticoid receptor DNA binding in rat lung. Eur f Pharmacol 1995;289:275-81.

11 Wong CS, Wahedna I, Pavord ID, et al. Effect of regular terbutaline and budesonide on bronchial reactivity to allergen challenge. Am $\mathcal{F}$ Respir Crit Care Med 1994;150:1268gen 73 .

12 Cockcroft DW, Swystun VA, Bhagat R. Interaction of inhaled $\beta_{2}$ agonist and inhaled corticosteroid on airway responsiveness to allergen and methacholine. Am $\mathcal{F}$ Respir Crit Care Med 1995;152:1485-9.

13 Hancox RJ, Cowan JO, Flannery EM, et al. Randomised trial of inhaled $\beta_{2}$-agonist, inhaled corticosteroid and their combination in the treatment of asthma. Thorax 1999:54: $482-7$.

14 Chai H, Farr RS, Froehlich LA, et al. Standardization of bronchial inhalation challenge procedures. I Allergy Clin Immunol 1975;56:323-7.

15 Adcock IM, Lane SJ, Brown CR, et al. Abnormal glucocorticoid receptor-activator protein 1 interaction in steroidresistant asthma. $\mathcal{F}$ Exp Med 1995;182:1951-8.

16 Workshop summary. Investigative use of bronchoscopy, lavage and bronchial biopsy in asthma and other airways diseases. Eur Respir f 1992;5:115-21.

17 Rosewicz S, McDonald AR, Maddux BA, et al. Mechanism of glucocorticoid receptor down-regulation by glucocortiof glucocorticoid receptor down-regu
coids. F Biol Chem 1988;263:2581-4.

18 Bellingham DL, Sar M, Cidlowski JA. Ligand-dependent down-regulation of stably transfected human glucocorticoid receptors is associated with the loss of functional glucocorticoid responsiveness. Mol Endocrinol 1992;6:2090102

19 Korn SH, Wouters EFM, Wesseling G, et al. In vitro and in vivo modulation of $\alpha$ - and $\beta$-glucocorticoid receptor mRNA in human bronchial epithelium. Am $\mathcal{F}$ Respir Crit Care Med 1997;155:1117-22.

20 Kalinyak JE, Dorin RI, Hoffman AR, et al. Tissue-specific regulation of glucocorticoid receptor mRNA by dexaregulation of glucocorticoid receptor $\mathrm{mR}$
methasone. $\mathcal{F}$ Biol Chem 1987;262:10441-4.

21 Svec F. The biopotency of dexamethasone at causing hepatic glucocorticoid receptor down-regulation in the intact mouse. Biochem Biophys Acta 1988;970:90-5.

22 Siebenlist U, Franzoso G, Brown K. Structure, regulation and function of NF-кB. Anпи Rev Cell Biol 1994;10:40555.

23 Auphan N, DiDonato JA, Rosette C, et al. Immunosuppression by glucocorticoids: inhibition of NF- $\mathrm{KB}$ activity through induction of IאB synthesis. Science 1995;270:28690.

24 Scheinman RI, Cogswell PC, Lofquist AK, et al. Role of transcriptional activation of I $\kappa \mathrm{B} \alpha$ in mediation of immunosuppression by glucocorticoids. Science 1995;270:283-6.

25 Brostjan C, Anrather J, Csizmadia V, et al. Glucocorticoidmediated repression of $\mathrm{NF} \kappa \mathrm{B}$ activity in endothelial cells does not involve induction of $\mathrm{I} \kappa \mathrm{B} \alpha$ synthesis. 7 Biol Chem 1996;271:19612-6.

26 Heck S, Bender K, Kullmann M, et al. IאB $\alpha$-independant downregulation of NF- $\kappa \mathrm{B}$ activity by glucocorticoid receptor. EMBO $71997 ; \mathbf{1 6}: 4698-707$. 